\title{
The BaSE Study: A Grounded Theory of Constructing Success for Bariatric Patients ${ }^{\dagger}$
}

\author{
Sara Lake *, Jane Coad and Janet Weber \\ Nutrition Science Department, School of Food and Advanced Technology, College of Sciences, \\ Massey University, Palmerston North 4442, New Zealand; j.coad@massey.ac.nz (J.C.); \\ j.l.weber@massey.ac.nz (J.W.) \\ * Correspondence: sara.lake@gmail.com; Tel.: +64-21-104-2631 \\ + Presented at the 2019 Annual Meeting of the Nutrition Society of New Zealand, Napier, New Zealand, \\ 28-29 November 2019.
}

Published: 21 January 2020

Bariatric surgery is an increasingly utilised method of establishing weight loss and resolving obesity-related comorbidities. However, the surgery requires and enforces a dramatic behaviour change which impacts on many aspects of patients' lives and there is a need for studies which examine the embodied patient experience. The Bariatric Surgery Experienced (BaSE) study used the qualitative methodology of Classic Grounded Theory to explore the lived experiences of 13 female patients in the period immediately before and up to 15 months after surgery. The result is a conceptually rich theory of Constructing Success for Bariatric Patients. The theory categorises and theoretically links key aspects of the peri-surgical period from the patients' perspectives. The main concerns driving the observed behaviour were Being Successful and Being Normal. The Being Successful construct comprised achieving the surgery, losing the excess weight and keeping it off. As time passed, Being Normal emerged as an aspect of success. These main concerns were frequently threatened by the demands of post-surgical life, leading to help-seeking and strategising actions which were categorised as Seeking Help and Information from Professionals, Establishing Networks, Self-Education and Self-Devised Strategies. The results of these actions were adaptions in behaviour and thought patterns, which ultimately impacted either positively or negatively on aspects of compliance with bariatric lifestyle requirements. There was also an aspect of Resigning or inaction which patients may slip into if they fail to resolve their issue, and a contextual category of Personal Factors which controlled the specifics of the process. Several areas pertinent to best practice were identified including medical professionals' approach to bariatric patients and larger bodies, level of psychological care provided, the value of ancillary professionals and the importance of suitable peer support. The impact of individual personal factors was identified as an area which may benefit from more research.

(C) 2020 by the authors. Licensee MDPI, Basel, Switzerland. This article is an open access article distributed under the terms and conditions of the Creative Commons Attribution (CC BY) license (http://creativecommons.org/licenses/by/4.0/). 